Brit. J. prev. soc. Med. (1975), 29, 40-47

\title{
Differential response to recall in a cervical screening programme
}

C. DIANNE SANSOM, JANET MACINERNEY, VALERIE OLIVER, JOHN WAKEFIELL

Department of Social Research, University Hospital of South Manchester, Christie Hospital and Holt Radium Institute, Withington, Manchester M20 9BX

\begin{abstract}
Sansom, C. Dianne, MacInerney, Janet, Oliver, Valerie, and Wakefield, J. (1975). British Journal of Preventive and Social Medicine, 29, 40-47. Differential response to recall in a cervical screening programme. Three years after a normal cervical smear, 1,007 women were followed up to see how they responded to a computer-generated recall letter. Seven women had died and 150 had had interim smears (mainly in association with regular contraceptive or postnatal examination). Of the remaining 850 , low response was not related to lower social class in the way initial recruitment to screening is. Working outside the home was more obviously associated with lower response, as was full-time compared with part-time work. Response was also related to where the first smear was taken $(61 \%$ of women first examined at a local authority clinic, but only $29 \%$ of those from a mobile industrial clinic) and was related to repetition of a familiar routine which favoured permanent rather than mobile facilities. Interviews with returners and non-returners showed that over $90 \%$ remembered receiving recall letters, so non-response was a conscious decision not to attend. When a first test originated at work, response to recall tended to be poor. Of the non-returners $42 \%$, but only $24 \%$ of the returners, had found the first test unpleasant or embarrassing. One-third of non-returners claimed difficulties in finding time, which is in accord with the lower response from full-time workers. Over $90 \%$ of those interviewed gave fear or modesty as the reasons why other women had not had a repeat smear. In general, differences in response to a letter inviting women to have a repeat smear are unlike those which characterize recruitment for a first smear. Consistency of experience appears to be strongly favoured in the regular use of cytological screening.
\end{abstract}

In the cervical screening programme in the Manchester region (for review, see Wakefield (1972)), all women whose previous test was negative are recalled by letter every three years.

Here we compare certain characteristics of 'returners' and 'non-returners'. As Kegeles (1967) suggested, we looked at a group about which something is known (that they had had a cervical smear three years earlier), then intervened (a letter of recall was sent) and measured subsequent behaviour. In this instance we were concerned more with behaviour than with attitudes. No control group was possible, because all women are sent a recall letter generated by computer three years after their last negative smear.

\section{Population Studied}

Our information was derived from two sources The first was the laboratory record cards of 1,007 women whose first cytotest had been normal if May 1968. They were followed up three years late when recall letters were sent. Seven had diech Another 150 had had a smear in the interim and so were not due for three-yearly recall. The remaining population of 850 was apparent $k_{y}$ eligible for recall.

Comparing the 150 interim users and the 859 'eligible' women as regards where they had had the first smear, only two notable differences emerge. Twice as many of the interim users had been first to a Family Planning Association clinic (30 
as against $15 \%$ ); and only one interim user had been first tested at an industrial clinic compared with $12 \%$ of the rest. This means that a larger proportion of interim users were already in a system which advocated regular, sometimes annual, tests. In fact the information on the record cards indicates that $40 \%$ of them had had smears more or less fortuitously on a routine revisit to a family planning clinic or their general practitioner for contraceptive advice, or when examined postnatally $(11 \%)$. Thirteen per cent presented with a new gynaecological condition. Thirty per cent were recorded as 'routine', though we know that this category is often used to mean routine contraceptive or postnatal examination. The remaining $6 \%$ were women called back by the laboratory at shorter intervals in an experimental part of the screening programme to determine the optimum period between recalls. There is nothing in these differences to suggest that the 850 eligible women would be uncharacteristic; they may in fact be rather more representative of women who enter the population screening system as a result of a positive decision on their part or that of their doctor.

The second source was two small surveys of (a) 53 women who responded to recall, and (b) 40 women who did not, both drawn from the population of 850 . They were interviewed at home by one of us (JM).

\section{DATA FROM LABORATORY RECORDS}

For the distinction between 'returners' and 'nonreturners' we have relied on information from the record cards and must acknowledge some inaccuracy. Administrative error, omission, and time-lag all occur in maintaining the records. Changes of address or of medical status are not always on record when the recall letters are sent out. The true response-rate is therefore higher than the crude rates quoted in this paper, but the relative differences between categories are not affected. A more realistic general rate of response to recall has been calculated as $65.7 \%$ (Sansom et al., in press).

Social Class and Response to Recall Participation in this screening programme has been monitored since it began (Wakefield and Barić, 1965; Wakefield and Sansom, 1966; Sansom, Wakefield, and Yule, 1970, 1971). In these studies, we concentrated on the initial recruitment of women to screening and found that it was biased in favour of women in higher social classes (classified by their husband's occupation). There was a concomitant under-representation of women from the two lower social classes, who are also at much greater risk. This class bias in recruitment was not found in the rates of response to recall of women who have once had a smear. If anything, it is slightly reversed, the response for classes I and II being $42 \cdot 8 \%$ and for classes IV and V $48 \cdot 7 \%$. This form of social classification is therefore not a useful criterion for distinguishing gross differences between those who do or do not respond. We therefore considered another-the employment status of the women themselves. Just over half (53.5\%) of the 850 women were housewives, $42.4 \%$ were working wives, and $4 \cdot 1 \%$ were single. The rate of response to recall (Table I) was higher in housewives generally $(53 \cdot 2 \%)$ than in working wives $(43 \cdot 3 \%)$. However, both housewives and working wives in social classes III manual, IV and V (classified according to their husband's occupation) had a better rate of response than their opposite numbers in classes I, II, and III non-manual. Only 7 of the 35 single women responded to the recall letter.

Working Wives AND Response to Recall An important trend over the last two decades has been the consistent increase in the proportion of married women who are 'economically active'. There was a 'dramatic change in the activity rates'

TABLE I

SOCIAL CLASS AND RESPONSE TO RECALL OF 'HOUSEWIVES' AND 'WORKING WIVES' (CLASSIFIED ACCORDING TO HUSBAND'S OCCUPATION)

\begin{tabular}{|c|c|c|c|c|c|c|c|c|}
\hline \multirow[b]{2}{*}{ Social Class } & \multicolumn{4}{|c|}{ Housewives } & \multicolumn{4}{|c|}{ Working Wives* } \\
\hline & Returners & $\begin{array}{l}\text { Non- } \\
\text { returners }\end{array}$ & Total & $\begin{array}{c}\text { Response } \\
\text { Rate } \%\end{array}$ & Returners & $\begin{array}{c}\text { Non- } \\
\text { returners }\end{array}$ & Total & $\begin{array}{c}\text { Response } \\
\text { Rate \% }\end{array}$ \\
\hline $\begin{array}{l}\text { I, II, and IIInm } \ldots \\
\text { IIIm, IV, and V } \cdots \\
\text { Unclassifiable and transient }\end{array}$ & $\begin{array}{r}82 \\
137 \\
23\end{array}$ & $\begin{array}{r}81 \\
114 \\
18\end{array}$ & $\begin{array}{r}163 \\
251 \\
41\end{array}$ & $\begin{array}{l}50 \cdot 3 \\
54 \cdot 6 \\
56 \cdot 1\end{array}$ & $\begin{array}{l}44 \\
98 \\
14\end{array}$ & $\begin{array}{r}71 \\
103 \\
30\end{array}$ & $\begin{array}{r}115 \\
201 \\
44\end{array}$ & $\begin{array}{l}38 \cdot 3 \\
48 \cdot 8 \\
31 \cdot 8\end{array}$ \\
\hline Total $\ldots$ & 242 & 213 & 455 & $53 \cdot 2$ & 156 & 204 & 360 & $43 \cdot 3$ \\
\hline
\end{tabular}

*Includes all widowed, divorced, and separated women as well as currently married women. The 35 single women have been excluded from this and subsequent analyses. 
for married women between 1951 and 1971 from $25.1 \%$ to $46.4 \%$ for women between the ages of 25 and 44 and from 21.5 to $53.4 \%$ for women of 45 to 59 . Moreover, 'this continued and marked increase in activity rates has occurred both amongst those with and those without dependent children'. (Central Statistical Office, 1973). This trend is of considerable importance for cytological screening programmes, since it occurs in the agerange in which suspicious/positive smears are most prevalent.

Our distinction between housewives and women who go out to work is therefore important: a low rate of response to recall is associated with an expanding category of women in the population. We considered the 360 working wives more closely and classified them by their own occupation. Most were doing either clerical jobs (class III nonmanual, $40.3 \%$ ) or semiskilled manual jobs (class IV, $28 \cdot 3 \%$ ). Grouping wives doing jobs in social classes I, II, and III non-manual in a 'white-collar' category, the rate of response was $40.1 \%$. For the 'blue-collar' category doing manual work (social classes III manual, IV and V) it was $48.7 \%$. So, whether working wives were classified on the basis of their own or their husband's occupation, there was a slightly better response at the lower end of the social scale.

ResPonse to Recall AND Source In this region, five different types of agency submit smears to the regional laboratory. Local authorities were responsible for two: the first and most usual is a clinic that is normally held in permanent premises with regular sessions for cervical screening; the second, specially arranged sessions at places of work, is here $\stackrel{\infty}{0}$ called 'industrial clinics'. Three other agencies? submit smears - general practitioners, Family Plan- $\bar{\Phi}$ ning Association clinics, and hospitals.

When the records of married women were $\stackrel{\vec{F}}{\vec{s}}$ analysed according to where they went for theiro first test (Table II), local authority clinics had provided the largest proportion of initial smears and $\overline{\bar{c}}$. had the best response-rate to recall $(61 \cdot 4 \%)$. The $\mathbb{\Phi}$ lowest response-rate $(29.4 \%)$ was that of women 0

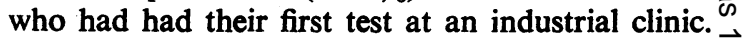
When working wives are distinguished from house- $\overrightarrow{0}$ wives (Table II, columns $2-3$ and 4-5) the rank $\overrightarrow{\vec{\omega}}$ order of the smear-taking agencies, in terms of $\stackrel{\omega}{\omega}$ response to recall, is not affected. Four of the $\bar{\Phi}$ agencies serve both housewives and working? women; industrial clinics are unique in that their clientele should consist only of working women (the nine who gave their occupation as 'housewife' must either be wrong or belong to the smallo numbers of friends and relatives of employees who have been permitted to attend these clinics. $?$ They have not therefore been accorded percentage values). The low response-rate from industrial clinies $\stackrel{5}{\supset}$ is therefore linked with the earlier finding of 10 response from 'working wives'.

Finally, the records showed that a womal generally returns for a second test to the kind of agency she went to for her first. Over $80 \%$ of all returners (Table III) went back to the same type of agency, but this conceals two extremes: $91 \cdot 1 \%$ of $\frac{\circ}{\Phi}$ returners first examined by their general practitioner went back to a general practitioner for the second test, whereas only $53.1 \%$ of the small number of returners first screened in industrial clinics went

TABLE II

SOURCE OF FIRST CYTOTEST AND RESPONSE TO SUBSEQUENT RECALL AMONG 'WORKING WIVES' AND 'HOUSEWIVES' $(n=815)$

\begin{tabular}{|c|c|c|c|c|c|c|c|c|c|c|c|}
\hline \multirow{2}{*}{\multicolumn{3}{|c|}{ Source of Test }} & \multicolumn{3}{|c|}{ Working Wives } & \multicolumn{3}{|c|}{ Housewives } & \multicolumn{3}{|c|}{ All Married Women } \\
\hline & & & \multicolumn{2}{|c|}{ Returners returners } & \multirow{2}{*}{$\frac{\begin{array}{c}\text { Total } \\
(100 \%)\end{array}}{117}$} & \multicolumn{2}{|c|}{ Returners $\begin{array}{c}\text { Non- } \\
\text { returners }\end{array}$} & \multirow{2}{*}{$\begin{array}{c}\begin{array}{c}\text { Total } \\
(100 \%)\end{array} \\
186\end{array}$} & \multirow{2}{*}{$\begin{array}{c}\text { Returners } \\
186\end{array}$} & $\begin{array}{c}\text { Non- } \\
\text { returners }\end{array}$ & \multirow{2}{*}{$\begin{array}{c}\begin{array}{c}\text { Total } \\
(100 \%)\end{array} \\
303\end{array}$} \\
\hline LHA & $\cdots$ & $\cdots$ & $\begin{array}{c}67 \\
(57 \cdot 3)\end{array}$ & $\begin{array}{c}50 \\
(42 \cdot 7)\end{array}$ & & $\begin{array}{c}119 \\
(64 \cdot 0)\end{array}$ & $\begin{array}{c}67 \\
(36 \cdot 0)\end{array}$ & & & $\begin{array}{c}117 \\
(38 \cdot 6)\end{array}$ & \\
\hline Family doctor .. & . & . & & & 88 & $\begin{array}{c}77 \\
(47 \cdot 8)\end{array}$ & $\begin{array}{c}84 \\
(52 \cdot 2)\end{array}$ & & $\begin{array}{l}119 \\
(47 \cdot 8)\end{array}$ & $\begin{array}{c}130 \\
(52 \cdot 2)\end{array}$ & 249 \\
\hline Hospital & $\cdots$ & $\cdots$ & & $(58 \cdot 3)$ & 12 & $\begin{array}{c}107 \\
10 \\
(45 \cdot 5)\end{array}$ & $(54 \cdot 5)$ & & $\begin{array}{c}(47 \cdot 8) \\
15 \\
(44 \cdot 1)\end{array}$ & $\begin{array}{c}(52 \cdot 2) \\
19 \\
(55 \cdot 9)\end{array}$ & 34 \\
\hline FPA $\ldots$ & $\cdots$ & $\cdots$ & $\begin{array}{c}17 \\
(34 \cdot 0)\end{array}$ & $\begin{array}{l}33 \\
(66 \cdot 0)\end{array}$ & 50 & $(40 \cdot 3)$ & $\begin{array}{c}46 \\
(59 \cdot 7)\end{array}$ & 77 & $\begin{array}{c}48 \\
(37 \cdot 8)\end{array}$ & $\begin{array}{c}79 \\
(62 \cdot 2)\end{array}$ & 127 \\
\hline Industrial clinic & $\cdots$ & . & $\begin{array}{c}25 \\
(26 \cdot 9)\end{array}$ & $\begin{array}{c}68 \\
(73 \cdot 1)\end{array}$ & 93 & & $4 *$ & $9 *$ & $\begin{array}{c}30 \\
(29 \cdot 4)\end{array}$ & $\begin{array}{c}72 \\
(70 \cdot 6)\end{array}$ & 102 \\
\hline Total & $\cdots$ & . & $\begin{array}{c}156 \\
(43 \cdot 3)\end{array}$ & $\begin{array}{l}204 \\
(56 \cdot 7)\end{array}$ & 360 & $\begin{array}{c}242 \\
(53 \cdot 2)\end{array}$ & $\begin{array}{l}213 \\
(46 \cdot 8)\end{array}$ & 455 & $\begin{array}{c}398 \\
(48 \cdot 8)\end{array}$ & $\begin{array}{c}417 \\
(51 \cdot 2)\end{array}$ & 815 \\
\hline
\end{tabular}

*Women anomalously classified as 'housewives' though attended clinic at place of work. Percentages are given in parentheses.

FPA $=$ Family Planning Association; $\quad$ LHA = Local Health Authority. 
TABLE III

TYPE OF AGENCY ATTENDED BY 'RETURNERS' FOR THEIR FIRST AND SECOND TESTS

\begin{tabular}{|c|c|c|c|}
\hline Agency & First Test & $\begin{array}{l}\text { Second Test } \\
\text { at Same } \\
\text { Agency }\end{array}$ & $\begin{array}{c}\text { Percentage } \\
\text { with Second } \\
\text { Test at Same } \\
\text { Agency }\end{array}$ \\
\hline 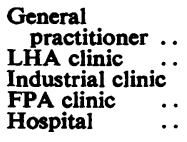 & $\begin{array}{r}123 \\
187 \\
32 \\
48 \\
15\end{array}$ & $\begin{array}{r}112 \\
165 \\
17 \\
28 \\
5\end{array}$ & $\begin{array}{l}91 \cdot 1 \\
88 \cdot 2 \\
53 \cdot 1 \\
58 \cdot 3 \\
33 \cdot 3\end{array}$ \\
\hline Total & 405 & 327 & $80 \cdot 7$ \\
\hline
\end{tabular}

back to an industrial clinic for the second test. Returners, therefore, are generally characterized as women who strongly favour consistency of experience with regard to the cytotest. For most, a repeat test is also the repetition of a similar type of medical consultation.

The findings regarding rates of response to a recall letter can be summarized thus:

(a) The employment status of women in a 'oncetested' population is associated with differential response to recall. Housewives respond better than working wives.

(b) Slightly higher rates of response to recall are associated with lower social classification (based on either own or husband's occupation).

(c) The types of agency where the initial tests were done were associated with different rates of response, some high (local authority clinics), others extremely low (industrial clinics).

(d) In general, the women who came for a second smear favoured repetition of the first experience and remained constant to one type of agency.

\section{Data from Sample Surveys}

Our second source of information came from two small surveys designed to supplement data from the records and provide additional clues to factors that might account for non-response.

How Women came to have Their First Test The 53 returners and the 40 non-returners were all asked how they came to have their first test (Table IV). Nearly four out of 10 of the returners said they had asked to have the test done, and three out of 10 that it had been suggested to them at work. Half the non-returners reported that it was first suggested at work and only two out of 10 had asked to have it done. Of the $\mathbf{3 0}$ women who had asked for the test, 26 went to local authority clinics for their first.
TABLE IV

HOW DID YOU COME TO HAVE YOUR FIRST TEST?

\begin{tabular}{|c|c|c|c|c|}
\hline \multicolumn{3}{|c|}{ Answer } & \multirow{2}{*}{$\frac{\text { Returners }}{21}$} & \multirow{2}{*}{$\frac{\text { Non-returners }}{9}$} \\
\hline Asked for it & $\cdots$ & $\cdots$ & & \\
\hline Part of another exa & ination & $\cdots$ & & \\
\hline Suggested by docto & clinic & $\cdots$ & $\begin{array}{c}5 \\
(9 \cdot 4)\end{array}$ & \\
\hline Suggested at work & $\ldots$ & . & $\begin{array}{c}16 \\
(30 \cdot 2)\end{array}$ & $\begin{array}{l}20 \\
(50 \cdot 0)\end{array}$ \\
\hline Don't know & .. & . & 1 & $(30)$ \\
\hline Totals & $\cdots$ & . & $\begin{array}{c}53 \\
(100 \cdot 0)\end{array}$ & $\begin{array}{c}40 \\
(100 \cdot 0)\end{array}$ \\
\hline
\end{tabular}

Percentages are given in parentheses

This provided one of the clues we were looking for. It suggests that when the incentive to have a first test has its origins in the work situation, it does not augur well for response to recall. This will be taken up later in our discussion of the combined results.

INDIVIDUAL EXPERIENCE OF THE TEST Two questions were asked about how women felt about the test. They were differently phrased and well separated in the interview schedule. The first was 'Was there anything about the test that you did not like?' and the second, 'Did you find the test unpleasant or embarrassing?' Of those who had not had a repeat smear, $42.5 \%$ had disliked some aspect of the test and/or found it unpleasant and embarrassing, but only $24.5 \%$ of those who had come for a repeat smear. Of the former category, over half had been to an industrial clinic for their first test.

Over $90 \%$ of all these women had their tests done by women doctors. We cannot, therefore, relate any shyness or embarrassment at having a smear taken by a man to the more general dislike of the test expressed by some women in the two study groups. Few women voiced any complaints about either the facilities at the agency they attended or the staff. Six women (three in each category) complained about the provisions for undressing. There were three complaints about lack of privacy, one about inadequate heat, and one about cramped conditions. Many women made favourable comments about the staff.

Organization of the Screening Services Women due for recall get two letters-a first invitation and then, two months later, a reminder to those for whom smears have not been received in the laboratory. Most women we interviewed remembered having received at least one or two 
TABLE V

RECOLLECTION OF RECEIVING RECALL LETTER AND REMINDER

\begin{tabular}{lll|c|c}
\hline \multicolumn{2}{c|}{ Answer } & & Returners & Non-returners \\
\hline Received one & $\ldots$ & $\ldots$ & $\begin{array}{c}36 \\
(67 \cdot 9)\end{array}$ & $\begin{array}{c}16 \\
(40 \cdot 0) \\
22 \\
13\end{array}$ \\
Received two & $\ldots$ & $\ldots$ & $(55 \cdot 0)$ \\
2 \\
Received none & $\ldots$ & $\ldots$ & 3 & $(5 \cdot 0)$ \\
No information & $\ldots$ & $\ldots$ & $(5 \cdot 7)$ & 0 \\
\hline Total & $\ldots$ & $\ldots$ & 1 & 53 \\
\end{tabular}

Percentages are given in parentheses

recall letters- $92.4 \%$ of returners and $95 \%$ of nonreturners (Table V)-so those who had failed to return knew they were due for a further test but had chosen not to return. Of the returners, $24.5 \%$ recalled having received two letters, which suggests that reminders do spur some women to action. When asked why they had had their latest test, $80 \%$ of the returners said it was because of the recall letter. The survey confirms our assumption that second smears received in the laboratory after the despatch of recall letters are a proper measure of response to the recall letter.

For many women, the single most important thing about the test is the result. Efficient organization of this aspect of the screening service is therefore crucial to their overall impression of the test. Eighty-three per cent of non-returners and $85 \%$ of returners remembered having received letters giving them the result of their first test. Two non-returners and four returners were told they would be informed only if the smear was not normal. Only one non-returner and two returners could not remember ever having heard anything about the result of their first test.

Two-thirds of the returners said they had received the result of their first test within two weeks. Fewer non-returners $(57 \cdot 5 \%)$ received the result within two weeks.

REASONS FOR NON-RESPONSE TO RECALL The non-returners were asked why they had not had a further test. The commonest answer (given by $32.5 \%$ ) was that they 'could not be bothered' or simply that it was 'inconvenient'. Eight women who were all working gave lack of time as a reason for not having another test-five because of family pressure, such as someone ill at home, and three because they were too busy at work. Four women were pregnant when the recall letter arrived and had not been for a test since.
Five women said they were afraid of cancer and of having further tests. Five said they had had difficulty in finding somewhere to go for a second test. Four of these had their first test in industrial clinics and one in hospital. Two of these had consulted their family doctor when the recall letter arrived but had been refused, one doctor remarking that it was 'not worth bothering about'; they did not know they could have a test at a local authority clinic, and their doctors had not given them this information.

Four non-returners had made appointments to have a second test but had broken them. One woman said she had had a period on the day of the appointment and, since her periods were irregular, it had not been worth making another appointment. The other three, having broken the previous appointment, were apprehensive about making another. They felt they had defied the system and were afraid of a rebuke if they tried to make another one. These comments illustrate the wide variety of reasons, or perhaps rationalizations, which women give for not responding to the recall letter. We thought that a different, and perhaps more accurate, reflection of women's reasons for not responding to recall might be given by the answer to a more impersonal question about the reasons for the behaviour of other women. The women were therefore asked why they though that other women had not had a repeat smeaf (Table VI). Two reasons-fear of the result and embarrassment about the test-dominated the answers. Two-thirds of the returners suggested fear of the result as the reason why other women had not attended, and a quarter that embarrassment was the chief reason. Fewer non-returners $(52 \%)$ gave fear of the result as the main reason for other women's not having a repeat smear and more said embarrassment was the reason. Davison and Clements (1971), reporting on a study in a depressed area of Manchester, also found striking differences between the reasons women gave for their own

TABLE VI

WHY OTHER WOMEN DO NOT COME FOR REPEAT SMEARS

\begin{tabular}{|c|c|c|c|c|}
\hline \multicolumn{3}{|c|}{ Answer } & Returners & Non-returners \\
\hline $\begin{array}{l}\text { Fear } \\
\text { Embarrassment } \\
\text { Don't know }\end{array}$ & $\begin{array}{l}\cdots \\
\cdots \\
\cdots\end{array}$ & $\begin{array}{l}\cdots \\
\cdots \\
\cdots\end{array}$ & $\begin{array}{c}35 \\
(66 \cdot 0) \\
14 \\
(26 \cdot 4) \\
4 \\
(7 \cdot 6)\end{array}$ & $\begin{array}{c}21 \\
(52 \cdot 0) \\
15 \\
(37 \cdot 5) \\
4 \\
(10 \cdot 5)\end{array}$ \\
\hline Total & $\cdots$ & $\cdots$ & $\begin{array}{c}53 \\
(100 \cdot 0)\end{array}$ & $\begin{array}{c}40 \\
(100 \cdot 0)\end{array}$ \\
\hline
\end{tabular}

Percentages are given in parentheses 
failure to have a test and the reasons they imputed to others. 'Fear' and 'modesty' were cited by $70 \%$ of the women as the reason for the behaviour of others, but only $14 \%$ gave these as their own reasons for not having had a test.

All were asked if they thought regular tests were a good idea, and only four non-returners said 'no'. Most women gave what was probably an 'acceptable' answer when asked if they intended to have further tests $-75.5 \%$ of returners and $67.5 \%$ of nonreturners. Equal proportions $(22 \cdot 5 \%)$ of both groups were uncertain. However, when all women who expressed either positive or ambivalent intentions about further tests were asked where they would go for a test, there were marked differences in the answers. Most returners (over $90 \%$ ) appeared to be quite satisfied with the first experience and intended to return to the same place for future tests, but only $41 \%$ of non-returners. It is notable that of the 21 non-returners who wanted to go somewhere different for further tests, 17 had had their initial test at an industrial clinic.

\section{Discussion}

The surveys provided no evidence to suggest that non-returners had been put off by maladministration or inefficiency. But prompt receipt of the results allays anxiety about the outcome of a test and may, therefore, contribute to a woman's willingness to subject herself to a similar experience.

Nine non-returners had made some effort to respond to the recall letter but were not resolute enough to overcome difficulties, ranging from uncooperative general practitioners to the inflexibility of appointment systems. Five of these nine women had been first tested at industrial clinics and one in hospital. The facilities they first used were not available at the time they were due for a second test, and so they had had to try to make other arrangements.

The surveys provided information that can be used in our interpretation of the data from the records. From the answers, and our knowledge of the scheme, it is possible to define the nature and logic of the demand made on women who are asked to submit to a second or subsequent test. This request, we argue, has several components.

In the first place, women who receive recall letters are being asked to submit to procedures for which they have a precedent in their own experience. The first component is self-evident: it is a request for repetition. Women are thought to be likely to respond to such a request only if they believe in the efficacy of cervical screening as a preventive health measure. Most of the women interviewed, whether returners or not, approved in principle of regular testing. For them, the demand for repetition was a reasonable one on medical grounds.

Next, we note that having a test has to be fitted into a woman's routine: she may believe that it is advisable to be screened, but taking a test is generally inconvenient. Those who said they 'couldn't be bothered' or 'didn't have the time' referred directly to the practical matter of allocating time and effort in order to be tested.

Finally, there is the conception of the cytotest as an experience that evokes an emotional reaction. Many of those who had not responded admitted that the vaginal examination disturbed and embarrassed them. The replies to the question about other women's reasons for not having a cytotest are probably an accurate reflection of women's own feelings about the test. The overwhelming majority said it was fear of the result and embarrassment that kept other women away. Most women experience some degree of anxiety and/or embarrassment over cervical screening.

In sum, when women are asked to respond to recall, they are being asked to:

(a) repeat a familiar experience,

(b) accept the rationale behind the request for regular tests,

(c) make the necessary adjustments to a daily routine, and

(d) overcome an emotional reaction to the test.

Returners conclude that the benefits that accrue from the knowledge that they are, for the moment, free of this form of cancer, outweigh the inconvenience and embarrassment of undergoing a cytotest; non-returners do not.

Data from the records showed a remarkable consistency on the part of returners in attending the same type of agency for both the first and second tests. It is notable that over half the nonreturners said they would want any future tests to be done at a different agency. In such circumstances the precedent already established must be broken. The experience of having a cytotest at a different agency is not a familiar one. Women who must change agencies for their second cytotest are in a position similar to that of new recruits to the screening programme, who must discover where and when they can get a test. This leads to the proposition that high response-rates to recall are encouraged if the same type of agency is available to do a second test. If a change is necessary, the risk of losing the client increases. 
The five agencies that provide the screening service each have certain characteristic features which either favour or hinder consistent use and hence either encourage or discourage a favourable response to recall. In terms of both the rate of response to recall and consistency of use, the local authority clinics have been the most successful. The clinics are established, accessible, have other health uses, hold special cytology sessions, and keep to a familiar routine. Special cytology sessions mean that many women attend solely to have a cytotest, and they are likely to be already aware of the benefits of regular examination. In our interview surveys, women who said they had asked for the test favoured local authority clinics above the other four agencies.

Much the same characteristics apply to family doctors, except that the business of arranging to have a test is not always so uncomplicated for the women. A more important point is that the general practitioners' unique opportunities for persuading women at risk to have a smear taken sometimes have a backlash when it comes to recall. If the women he has persuaded-perhaps when they attend for another purpose-are not adequately informed of what is being done and why, substantial numbers of women remain unsure or even unaware of the need for regular re-examination (Sansom, Wakefield, and Pinnock, 1971).

At family planning clinics, with few exceptions, smears are taken only as an adjunct to the provision of some form of contraception, so cytotests tend to be thought of as something to do with family planning and not as a preventive health routine of any special importance. The clinics share some characteristics of the other two established agencies but they are not readily accessible to women who want to go for cytological examination only.

The mobile industrial clinics are set up by local authorities and use the same personnel. But these are the only points of similarity with the static local authority clinics. Women do not have to take the initiative or make arrangements for themselves; the test is brought to them at work. All this takes place outside the usual context of medical behaviour. Work-mates provide mutual support, and the test becomes more a part of the work situation, so women who are first examined at a mobile industrial clinic often have little or no commitment to the rationale of cervical screening. Even more important is that the same facilities are not readily accessible to all their original clients when recall letters go out. The industrial clinic teams are mobile and, to be effective, have to return to the workplace soon after the recall letters go out. There can be little flexibility in the arrangements: women either attend $\stackrel{\infty}{\circ}$ when the team comes or not. Some of the women have changed jobs, become housewives, are away on the days the team visits, are menstruating, or ? are ill. It is paradoxical that the characteristics which $\overrightarrow{\vec{F}}$ make the mobile clinics an effective means of getting women at risk to have a first smear are $\frac{\bar{C}}{0}$ those which militate against a high response to $\frac{\overline{\mathrm{C}}}{\mathrm{D}}$ recall. Nevertheless, mobile industrial clinics provide $\overparen{\mathbb{}}$ a service for a large and still expanding section of $\frac{\mathrm{Q}}{\mathrm{D}}$ the female population-working wives. This asso- $\omega$ ciation between an agency characterized by features $\overrightarrow{0}$ which discourage regular cervical screening and the $\overrightarrow{ }$ category of women with the lowest response reveals $\omega_{\sigma}$ a serious problem for the organizers: the mobile $\frac{\sigma}{\sigma}$ clinics specially set up to cater for the initial $\frac{}{5}$ needs of an expanding social category are the least successful in promoting subsequent response to recall. This point may well be worthy of investigation ${ }_{0}$ later in relation to the mobile caravan units now in

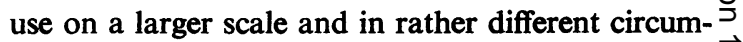
stances by the Women's National Cancer Control Campaign.

The findings discussed here, taken with our $\stackrel{\frac{\rho}{3}}{\frac{1}{3}}$ earlier studies (Wakefield, 1972) make it clear that $\vec{\bullet}$ the factors associated with differences in respon\&e to persuasion to have a first smear are not those associated with response to a recall letter. Mosit notably, social class differences operate, if anything, in reverse once women have had a first smear. They suggest strongly that the regular use of a cervical

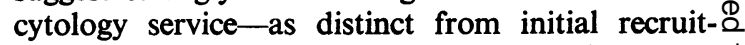
ment-depends substantially on providing most $\vec{\circ}$ of the facilities through community clinics and 3 family doctors. But they have to be flexible enough in their time-tables to cater for working women? and readily accessible with the minimum of administrative fuss to potential users. Consistency of experience appears to be what women look for most in this situation.

We are indebted to Dr. Robert Yule for providing the original data on which this investigation was based.

The study was financed by the Department of Health and Social Security.

\section{REFERENCES}

Central Statistical OfFice (1973). Social commentary. 응 Social Trends, 4, 6. HMSO, London.

Davison, R. L. and Clements, Judith E. (1971). Why don't they attend for a cytotest? A pilot study among a high-risk population. Med. Offr, 125, 329. $\frac{\mathrm{C}}{\mathrm{D}}$

Kegeles, S. S. (1967). Attitudes and behaviour of the + public regarding cervical cytology: current findings $\square$ and new directions for research.J. chron. Dis. 20,911. 
Sansom, C. Dianne, MacInerney, Janet, Oliver, VALERIE, WAKEFIELD, J. and YULe, R. (1975). Recall of women in cervical screening programme: an estimate of the true rate of response. Brit. J. prev. soc. Med. (in press).

Wakefield, J., and Pinnock, Katherine M. (1971). Choice or chance? How women come to have a cytotest done by their family doctors. Int. J. Hlth Educ., 114, 54.

, - - and Yule, R. (1970). Cervical cytology in the Manchester Region: changing patterns of response. Med. Offr, 123, 357. $\longrightarrow$, - and - (1971). Trends in cytological screening in the Manchester area 1965-71. Community Medicine, 126, 253.

Wakefield, J. (1972) (Ed.). Seek Wisely to Prevent. HMSO, London.

and BArIć, L. (1965). Public and professional attitudes to a screening programme for cancer of the uterine cervix. Brit. J. prev. soc. Med., 19, 151.

- and Sansom, C. Dianne (1966). Profile of a population of women who have undergone a cervical smear examination. Med. Offr, 116, 145.

Requests for reprints to Dr. John Wakefield, The Department of Social Research, Christic Hospital and Holt Radium Institute, Manchester M20 9BX. 